\title{
Workshop
}

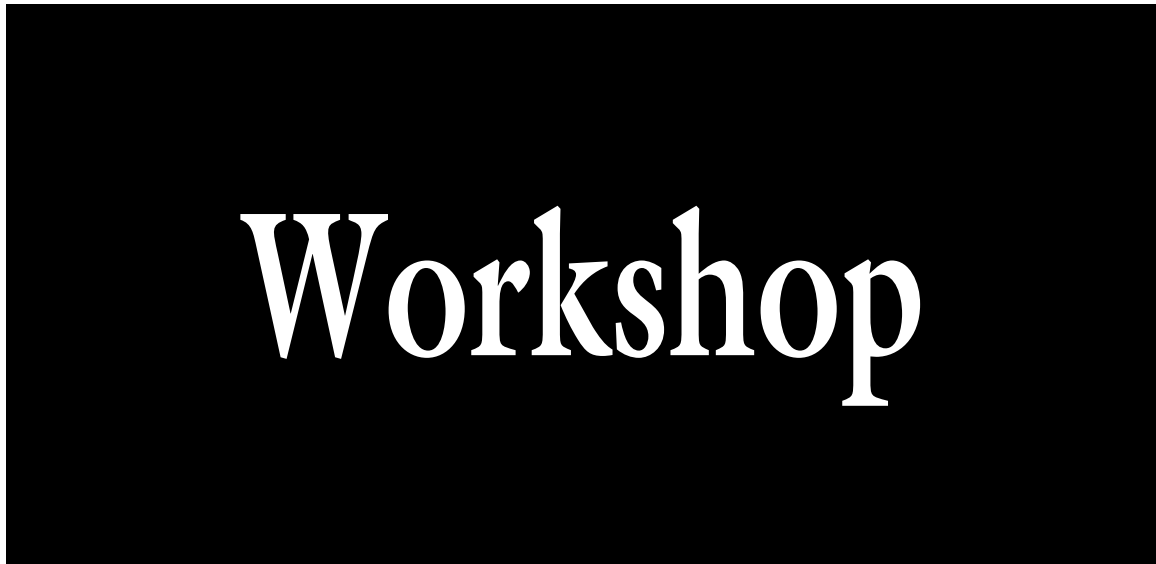

\section{Foliar Nutrition to Enhance Horticultural Crop Production and Quality: An Introduction}

\section{Bielinski M. Santos ${ }^{1}$}

$\mathrm{F}$ oliar nutrition is an important management strategy to improve performance of vegetable and fruit crops. This technology has been used for decades to enhance nutrient absorption and utilization in three critical conditions of crops, namely: 1) during high-demand periods, especially when the soil cannot supply nutrients fast enough for rapid tissue expansion; 2) when fertilizer application to the soil is impossible or the environmental conditions would reduce its effectiveness; and 3) when application of a given fertilizer source to the soil could result in high nutrient fixing and unavailability.

The objectives of the workshop were 1 ) to provide the science framework for using foliar nutrition in vegetable and fruit crops and 2) to discuss the conditions for its implementation.
On the first objective, the physiological and environmental aspects of foliar nutrient application, absorption, and assimilation were discussed over a broad range of crops, with special emphasis on vegetables and fruit trees. On the second objective, the practical application of fertilizer sources, application techniques, deficiency monitoring and correction, and limitations of the technologies were presented. Four out of the six papers are presented in this publication of the workshop, including research on diverse foliar fertilization aspects, such as the effects of timing of nitrogen fertilization on avocado (Persea americana) and citrus (Citrussp.) in California, foliar nutrient uptake and nitrogen and calcium application on apple (Malus $\times$ domestica), potassium and iron sources on muskmelon (Cucumis melo), and tomato
(Solanum lycopersicum) in Texas and Florida, respectively. These papers illustrate the current challenges and potential future practices on foliar fertilization of horticultural crops.

The article on timing of foliar fertilization in avocado and citrus discussed the most important aspects of this type of fertilization on fruit trees and the needed conditions for success. Also, it dealt with identification of stages in tree phenology when application of low-biuret urea improves fruit yield and quality. The effects of this fertilizer source on inflorescence and ovule viability were also discussed. Another paper described recent research on developing foliar spray programs that enhance nutrient availability, reduce nutrient requirements, and minimize release of potentially deleterious elements into the environment. The influence of foliar urea and calcium sprays on apple was also examined.

On the vegetable side, a paper on muskmelon described the effects of potassium foliar sources on important fruit traits, such as soluble solids, ascorbic acid, beta carotene, sugar, aroma, appearance, and texture. The authors emphasized the influence of environmental conditions and production practices on the timing of foliar potassium application, as well as the suitability of potential sources. The last paper focused on corrective foliar applications of iron in tomato using several organic and inorganic sources. Considerations on soil $\mathrm{pH}$ and organic matter content modifications to improve absorption were presented. 